\title{
“A FUNÇÃO MEDIADORA DA IMAGEM FOTOGRÁFICA!"
}

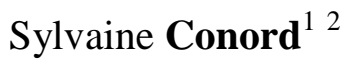

A imagem tem inúmeras atualizações potenciais, algumas se dirigem aos nossos sentidos, outros unicamente ao nosso intelecto. É preciso dizer primeiramente que, sem desconhecer essa multiplicidade de sentido, limitaremo-nos aqui a uma variedade de imagens, aquelas com forma visível, as imagens visuais (Aumont, 1990: 3), e mais particularmente as imagens fotográficas.

É importante levar em conta inicialmente a especificidade do suporte fotográfico ligada a sua natureza técnica. Definida por Philippe Dubois como uma impressão luminosa (Dubois, 1990: 46), a fotografia tem uma força representacional face às exigências da complexidade da vida social (Piette, 2007) que faz com que seu uso seja pertinente no âmbito da pesquisa em ciências humanas. Ela constitui uma imagem indicadora segundo Charles Peirce que se distingue do ícone (representação por semelhança) e do símbolo (representação por convenção) e se aparenta com essa categoria de sinais onde se encontra também a fumaça (indício do fogo), a sombra (índício de uma presença), a cicatriz (marca de um ferimento), a impressão de passo, etc. (Dubois, op.cit.). Essas características oferecem ao pesquisador a possibilidade de memorizar os "vestígios" do real com uma relativa exatidão. O registro de múltiplos detalhes que o olho nu não conseguiria memorizar por completo privilegia um acesso ao real que parece sem obstáculo. No entanto a intervenção do pesquisador fotógrafo nas escolhas de "mises en scène" e de enquadramentos implica necessariamente em uma perda de objetividade na relação que este entretém com as realidades sociais que observa. Outra possibilidade consiste em colocar as tomadas fotográficas e a imagem visível na tela ou impressa em papel no centro das interações com objetivo de compreender sua própria subjetividade e a do sujeito fotografado. A função mediadora da imagem fixa confirma a possibilidade de considerar a fotografia como um modo de conhecimento, o que podemos verificar através das diversas experiências de campo.

\footnotetext{
${ }^{1}$ Universidade Paris Oeste Nanterre La Défense, França.

2 Professora de Sociologia na Universidade Paris Oeste Nanterre La Défense, membro do IAP LAU (EHESS/CNRS) sylvaine.conord@u-paris10.fr.
} 


\section{Imagem mediática}

Essa reflexão nasceu de práticas fotográficas pessoais e profissionais que representam ao mesmo tempo a expressão de uma "paixão ordinária" no sentido contemporâneo definido por Christian Bromberger, ou seja, "uma orientação afetiva estável em relação a um objeto singular" (Bromberger, 1998: 25), e da experiência das técnicas de tomadas fotográficas aplicadas a diversas situações em meio urbano. Uma delas diz respeito ao trabalho sobre a cidade dos 4000*, em La Courneuve, situada na periferia parisiense ${ }^{3}$. Eu estava incumbida de tirar as fotos no âmbito de um programa de pesquisa sobre o vínculo social. O objetivo desse procedimento era experimentar um método a fim de compreender de que forma a fotografia podia ajudar o pesquisador a apreender as maneiras de viver e de perceber o espaço urbano (espaço público, espaço doméstico, cidade em meio à periferia). Na esfera de um estudo aprofundado sobre irmãos originários dos Aurès na Argélia, tivemos a oportunidade de entrar em contato com a maioria dos membros dessa família grande. Aos poucos, graças à condução de entrevistas, recolhíamos elementos de compreensão sobre as diferentes trajetórias de vida, entre os que haviam decidido a todo custo sair de La Courneuve conhecida como uma região difícil, os que haviam voltado para a Argélia, e os que haviam escolhido ficar na cidade dos 4000 que consideravam um pouco como sua cidade. A família do pequeno Yanis (foto 1) pertencia a essa última categoria. Ela morava no alto do grande prédio horizontal situado no centro do bairro por escolha e não por obrigação segundo relatos de campo. Sem as entrevistas não teríamos compreendido os limites da percepção imediata dessa imagem feita de acordo com os critérios de uma foto mediática sobre as periferias (representada sob o ângulo da exclusão).

$$
* * *
$$

\footnotetext{
* N. T. Cidade dos 4000 é um conjunto de prédios situado na periferia de Paris cuja população é formada majoritariamente por famílias repatriadas da África do Norte, entre eles judeus; norte-africanos e outras nacionalidades.

${ }^{3}$ Ethnobiography d'une famille originaire des Aurès à La Courneuve, Dir. Renée Vigneron, 1993, Relatório de Pesquisa, Plano Urbano, FAS, Ministério da Cultura.
} 


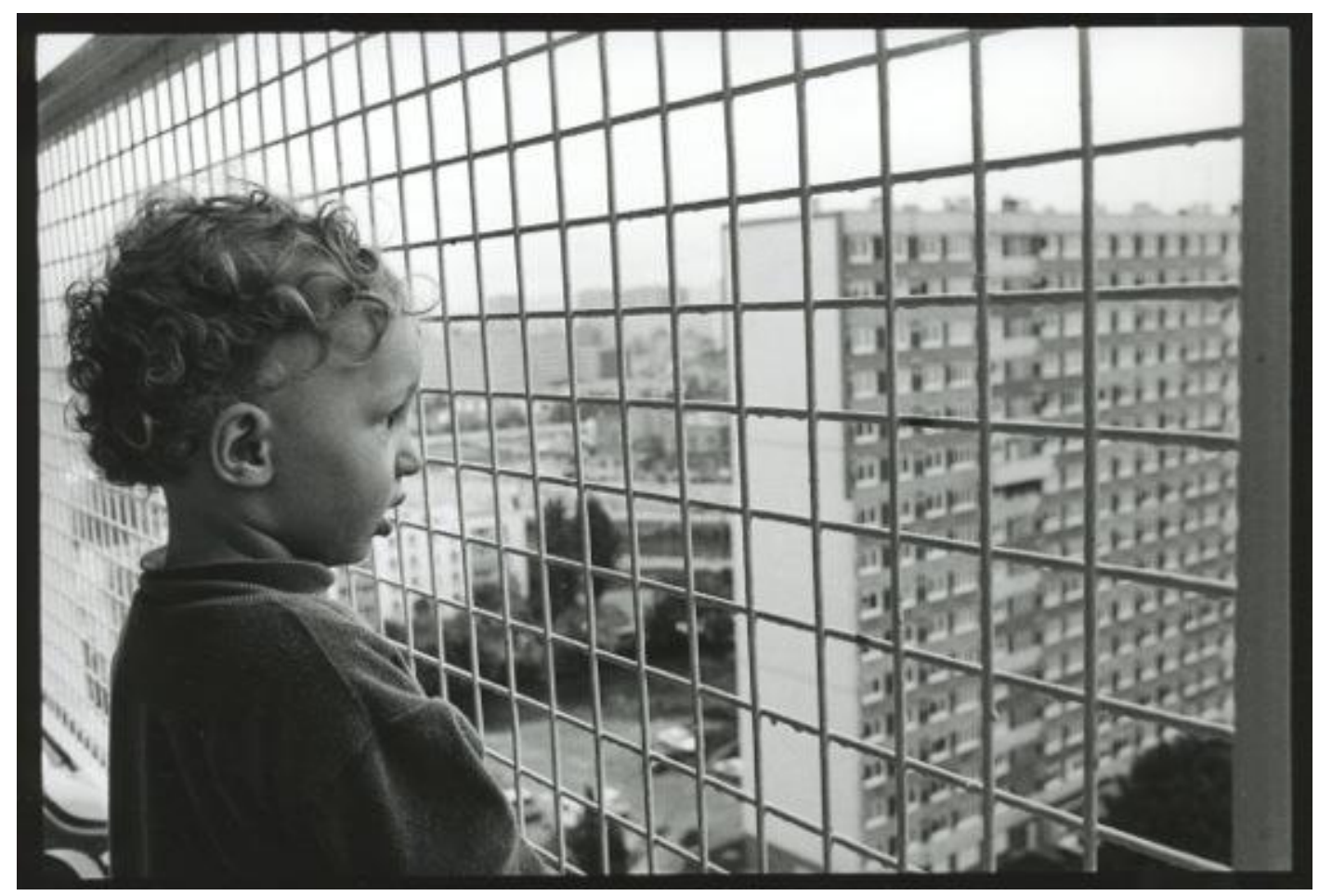

Foto 1 - Yanis na cidade dos 4000 em La Courneuve, (c) Sylvaine Conord.

Com efeito, o conjunto das escolhas técnicas e estéticas acentua a ideia de medo, de enclausuramento, de insegurança de um meio inacessível: o enquadramento fechado, a fotografia tirada na altura da criança com uma objetiva grande-angular, os jogos de perspectiva entre a grade da sacada, a pequena profundidade do campo que vem a reforçar a presença da grade, a altura e a monotonia dos elementos do prédio no plano de fundo, a escolha de marcar em filme ${ }^{4}$ essa expressão da criança que parece perplexa. É a imagem que quis fazer de acordo com minha percepção subjetiva dos lugares. À primeira vista essa paisagem me parecia inumana. Ora a função mediadora da fotografia compreendida como uma ferramenta colocada no centro do processo de investigação me permite relativizar essa imagem da cidade. $\mathrm{O}$ cruzamento dos dados entre fotos e relatos coletados junto aos membros da família que ficaram em La Courneuve trazia um olhar diferente sobre a cidade considerada, principalmente por esta família, como um lugar de vida e não de exclusão. Era preciso que eu reconhecesse que minhas escolhas de tomadas eram particularmente orientadas. A posição do corpo da fotografia de frente ao invés de estar agachada no momento da foto teria permitido mostrar que a grade não era

\footnotetext{
${ }^{4}$ A fotografia foi em negativo antes de ser digitalizada.
} 
muito alta. Um enquadramento maior teria tornado visível os brinquedos da criança ao redor dela (uma bicicleta que estava sendo usada antes de tirar a foto). Outro momento escolhido para o clique da foto teria mostrado uma criança sorridente. Enfim uma fotografia dos pais teria nos dado informações sobre o contexto familiar e afetivo de Yanis.

Não estou demonstrando, porém que a imagem é sistematicamente enganadora, deformadora das realidades que ela nos mostra. Gostaria de chamar atenção aqui para a importância de contextualizar a fotografia, no domínio de um procedimento científico, dando elementos que dizem respeito ao fora de campo do ponto de vista do fotógrafo e daquele das pessoas fotografadas.

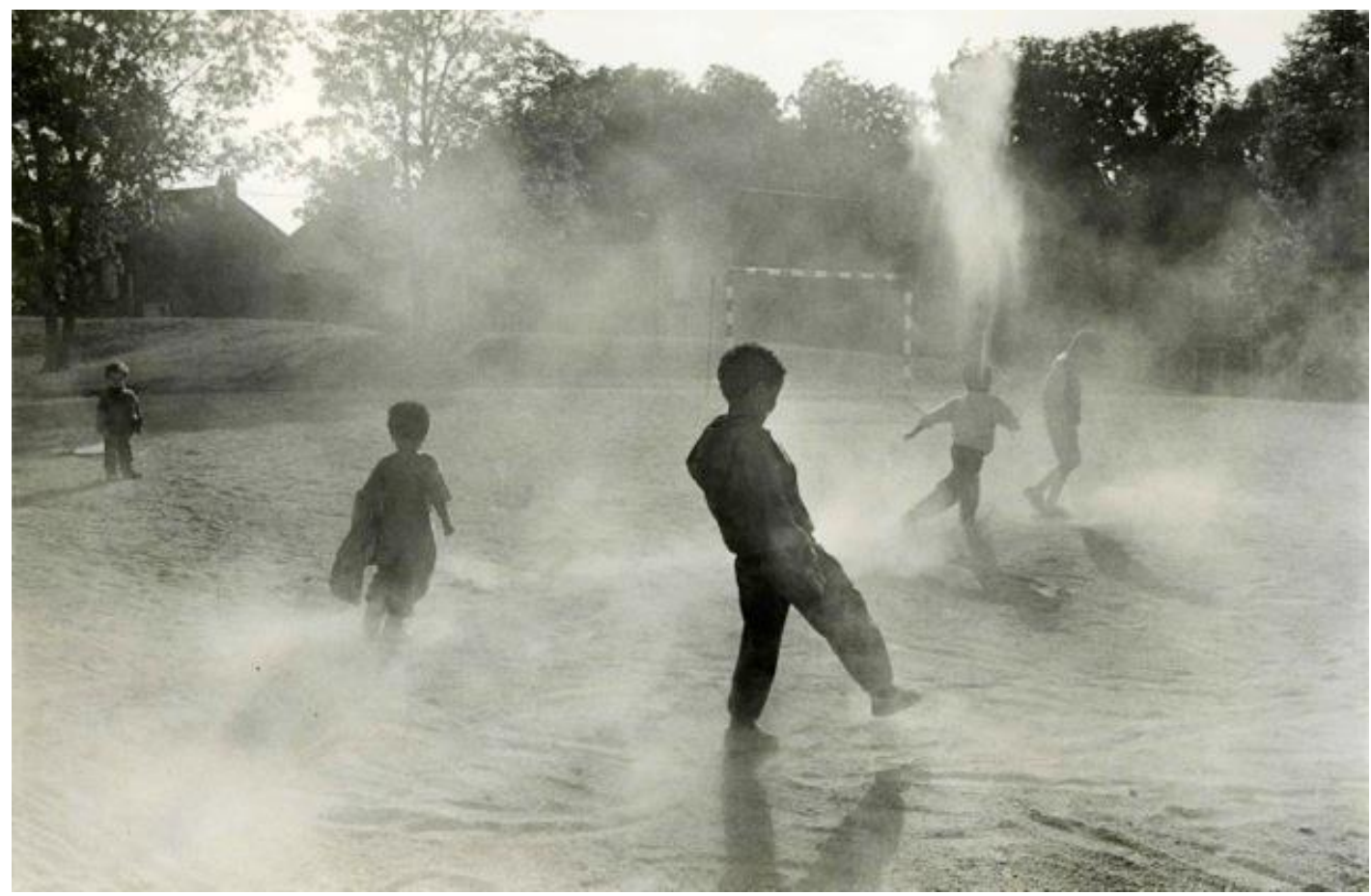

Foto 2 - Verão em Valenton, (C) Sylvaine Conord.

Duas outras imagens da periferia parisiense (foto 2, foto 3) mostram uma realidade completamente diferente. Desprovidas de informações sobre o fora do quadro, elas mostram uma cena acolhedora, espaços de jogos ensolarados que se poderia 
encontrar em qualquer lugar. Todavia esse cenário faz parte também das realidades dos meios periurbanos da mesma forma que a paisagem mostrada na foto 1 . O interesse pelo registro de imagens é multiplicar os pontos de vista com intuito de objetivar os enquadramentos e fixar elementos que nos permitam apreender de maneira sensível os espaços urbanos (Conord, 2002; 2008). O campo é múltiplo: trata-se de registrar os limites, os sinais visíveis, os códigos, os vestígios, os contornos e os caminhos.

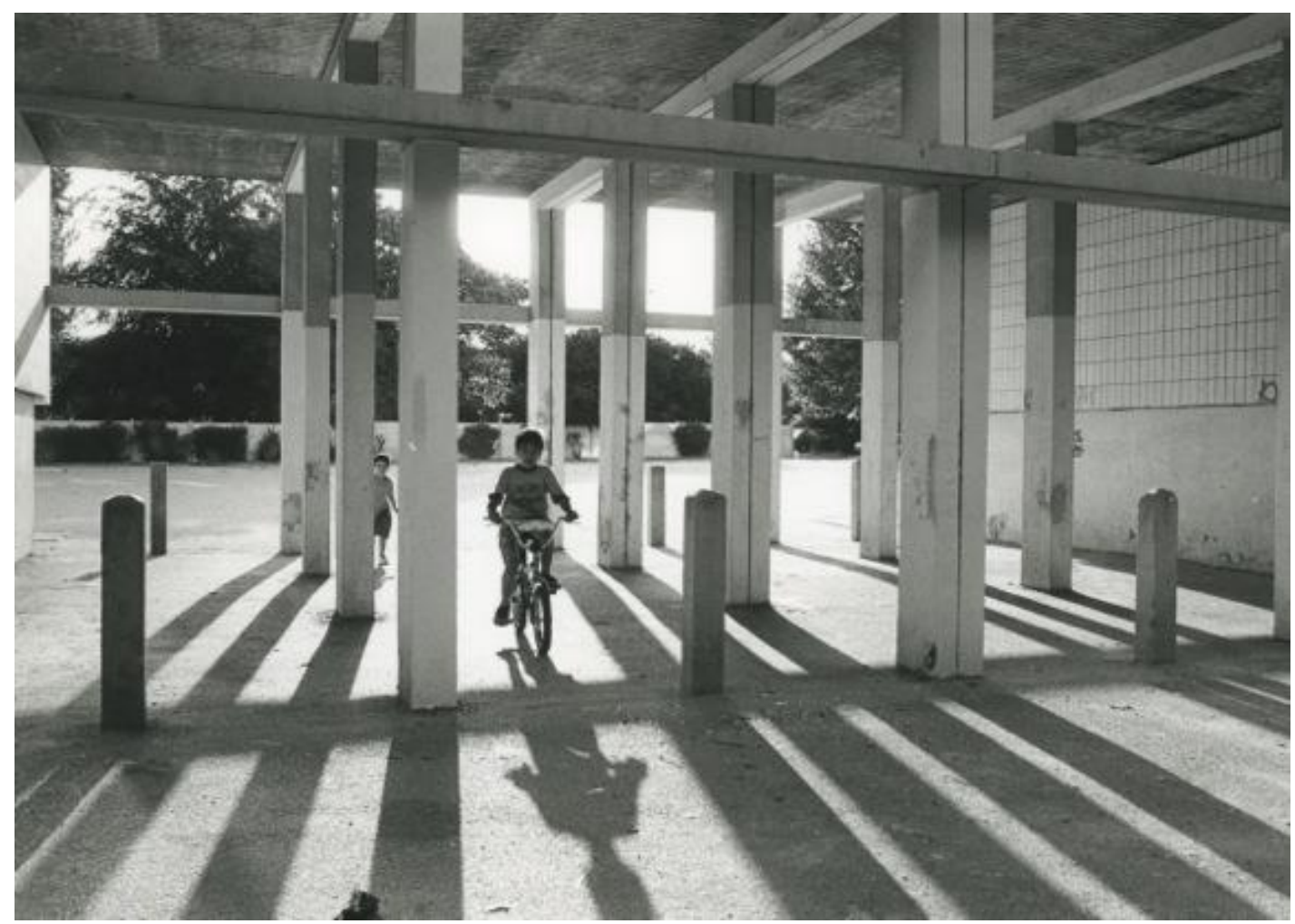

Foto 3 - Em Villejuif, (c) Sylvaine Conord.

\section{Reconhecimento do lugar}

Outra experiência de tomadas realizadas no Marrocos durante um trabalho de pesquisa sobre um cemitério desafetado de Salé ${ }^{5}$ me levou a estabelecer um método específico na observação de um lugar. O antropólogo e fotógrafo John Collier emprega

\footnotetext{
${ }^{5}$ Tese de doutorado, Pascale Philifert, 1998. Espaces de mort, espaces de vie? Une approche des cimetières au Maroc, IUP, Universidade Paris XII - Val de Marne.
} 
os termos "mapping and surveying" que pertencem habitualmente ao registro do geógrafo. Ele insiste na importância desta primeira etapa em uma pesquisa que ele chama de "photographing the overview":

In addition to general human orientation and rapport building, the first phase of fielwork usually includes a variety of descriptive operations, outlining cultural geography and environment as a frame of reference within which the structured research goals can be accomplished. Usually this envolves a mapping and sketching in of environmental areas. Here a camera serves a logical function.

(Collier, 1986: 29)

Encontramos aqui as origens de um procedimento de caráter geográfico. Para o geógrafo Jean Brunhes (1860-1930) a fotografia que ele praticava como expert é um instrumento essencial, tanto para suas pesquisas quanto para seu ensino. Quando descrevia as paisagens com a ajuda da imagem fixa, ele detalhava as cores, as linhas, as texturas. Para realizar um tipo de inventário fotográfico dos espaços, seu método compreendia a vista direta, o registro foto e a pesquisa oral.

Essa fase de reconhecimento permite igualmente apreender os diversos constrangimentos. Após ter fotografado diferentes elementos desse cemitério como os detalhes da disposição das tumbas, a organização espacial, a descrição do marabuto, decidi registrar mais precisamente imagens relativas às práticas sociais que são observadas nos locais como mulheres bordando e outras preparando chá de menta. É necessário nesse estágio se questionar sobre as relações entre constrangimentos técnicos e opções metodológicas. Quando duas mulheres sentadas no chão não queriam mais ser fotografadas, propus-lhes fotografar apenas seus pés e os instrumentos necessários para servir o chá (foto 4). 


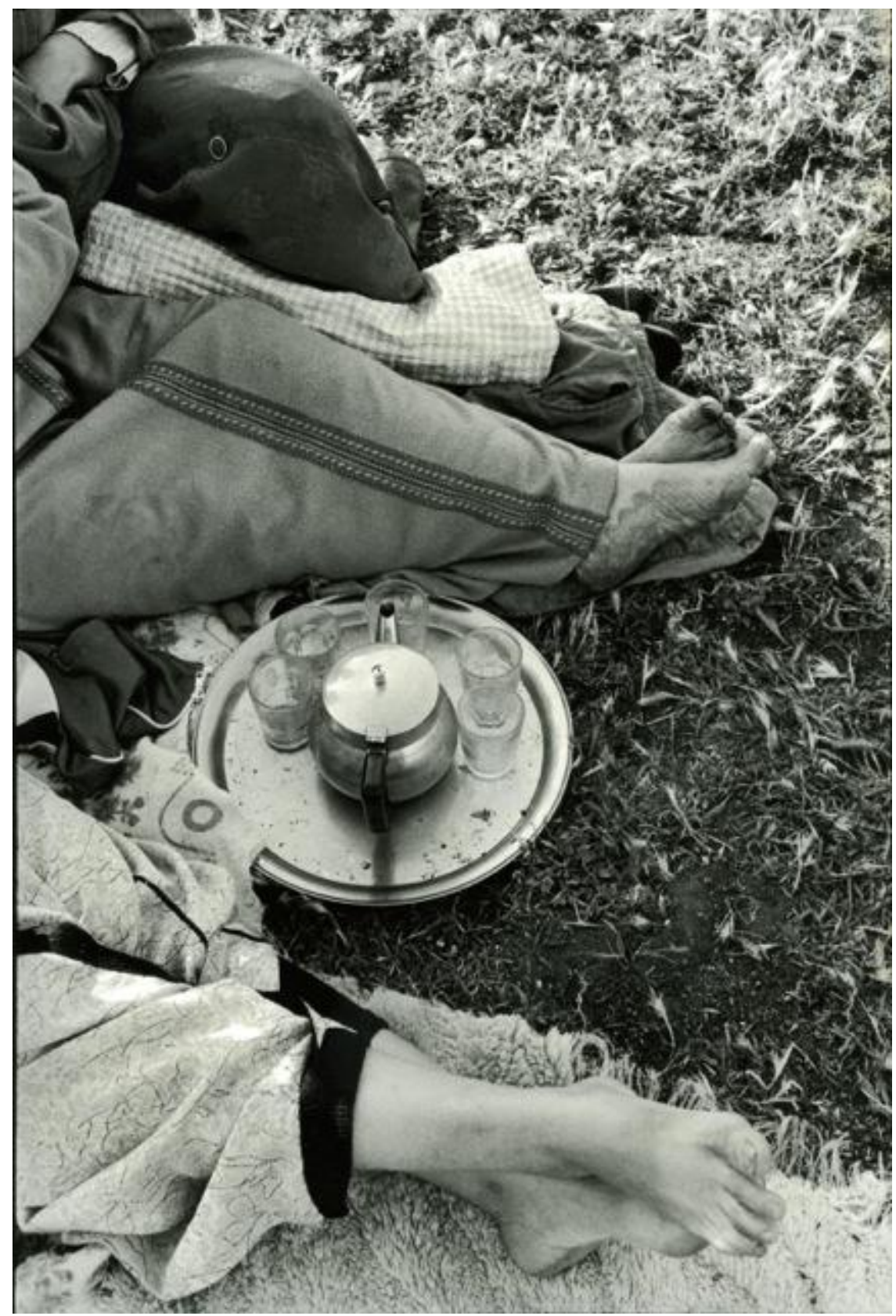

Foto 4 - Na hora do chá, cemitério desafetado de Salé, Marrocos, (c) Sylvaine Conord.

Os passeios no campo, o estudo da luz, da posição dos elementos e dos objetos, a observação das reações das primeiras pessoas encontradas e das opções de enquadramento permitem avaliar as possibilidades técnicas. Para a foto 4 um constragimento imposto pelas pessoas fotografadas permitiu finalmente à fotógrafa produzir uma imagem que apresenta, além de sua qualidade estética, uma dimensão etnográfica. Com efeito, graças ao que é mostrado, é possível descrever precisamente os 
diferentes objetos (o bule, os copos, a bandeja) que servem para a preparação e degustação do chá, os ornamentos corporais (tatuagens, arabescos nos pés) que confirmam por meio de uma lenda a natureza insólita do lugar onde se dá a cena, o cemitério de Salé.

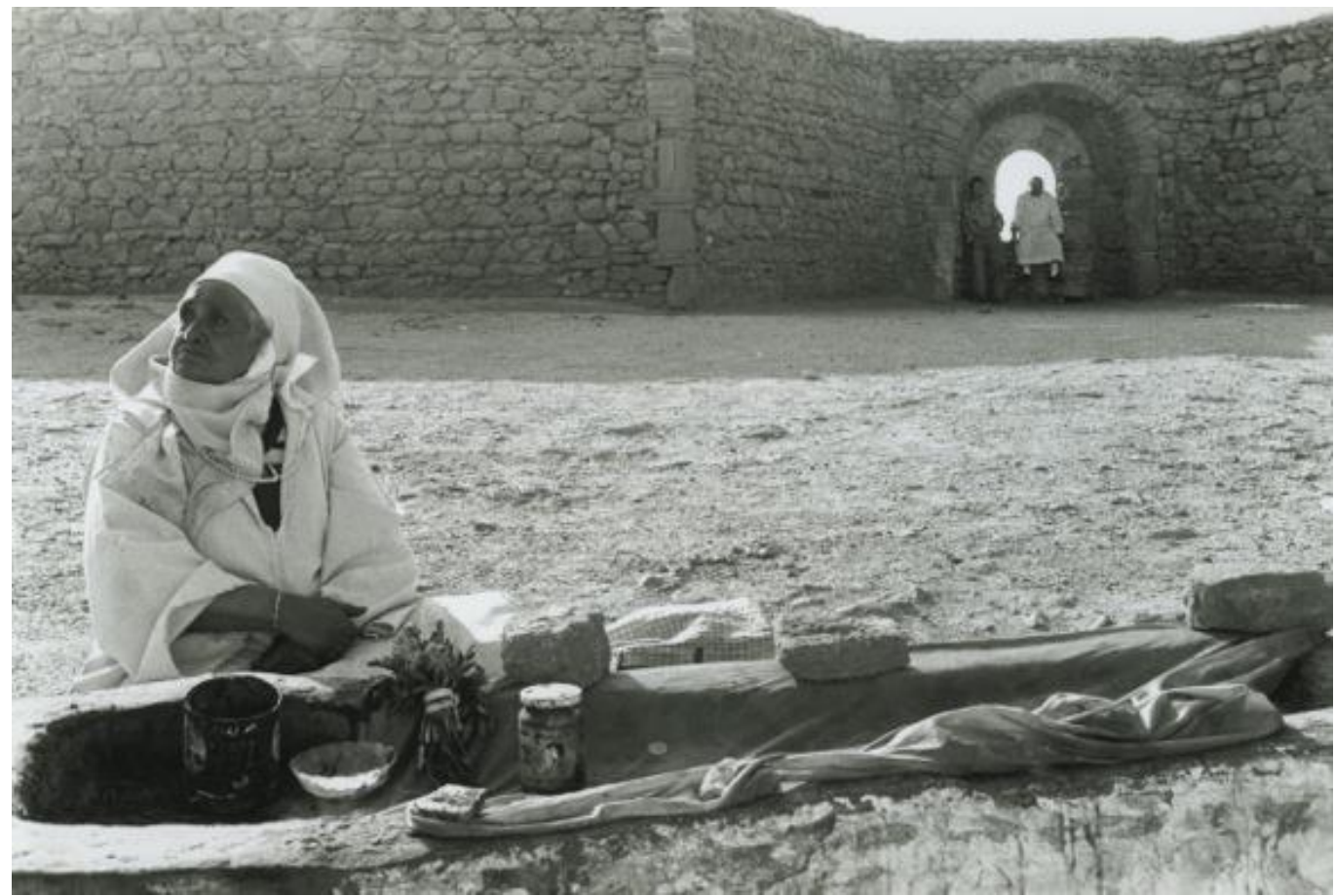

Foto 5 - Mulher marroquina orando, cemitério de Salé, (c) Sylvaine Conord.

\section{Mise en scène}

Uma outra mulher orando sobre um túmulo aceitou ser fotografada (foto 5). Para fazer esse retrato, escolhi uma objetiva grande-angular que me permitiu levar em conta o espaço entorno do indivíduo (túmulo, muros, personagens no segundo plano). O fotógrafo e desenhista Henri Cartier-Bresson escreveu:

Uma das características emocionantes do retrato é também encontrar a semelhança dos homens, sua continuidade através de tudo o que descreve seu meio; como em um álbum de família, confundir o tio com seu sobrinho. (...) Ele (o fotógrafo) terá que respeitar o ambiente, integrar o habitat que descreve o meio, evitar, sobretudo o 
artifício que mata a verdade humana e também fazer esquecer a máquina fotográfica e aquele que está manipulando-a.

(Cartier-Bresson, 1985: 14)

A realização de um retrato é um exercício difícil que requer competências e sensibilidade da parte do antropólogo-fotógrafo. Qual a melhor maneira de compreender um indivíduo e seu contexto social? A observação das reações das primeiras pessoas encontradas permite avaliar as possibilidades técnicas e humanas. Como a do cineasta (De France, 1982: 272) a atitude do fotógrafo é muito dependente dos constrangimentos técnicos e da forte visibilidade de seu material fotográfico. Há sempre um tempo mais ou menos longo de negociação (para a aceitação da tomada) e depois um tempo para conhecer o sujeito. $\mathrm{O}$ ato de tomadas e as imagens realizadas dispostas no centro das trocas revelam aspectos do campo e na maioria dos casos, ajudam consideravelmente a aceitação do pesquisador pelas pessoas observadas.

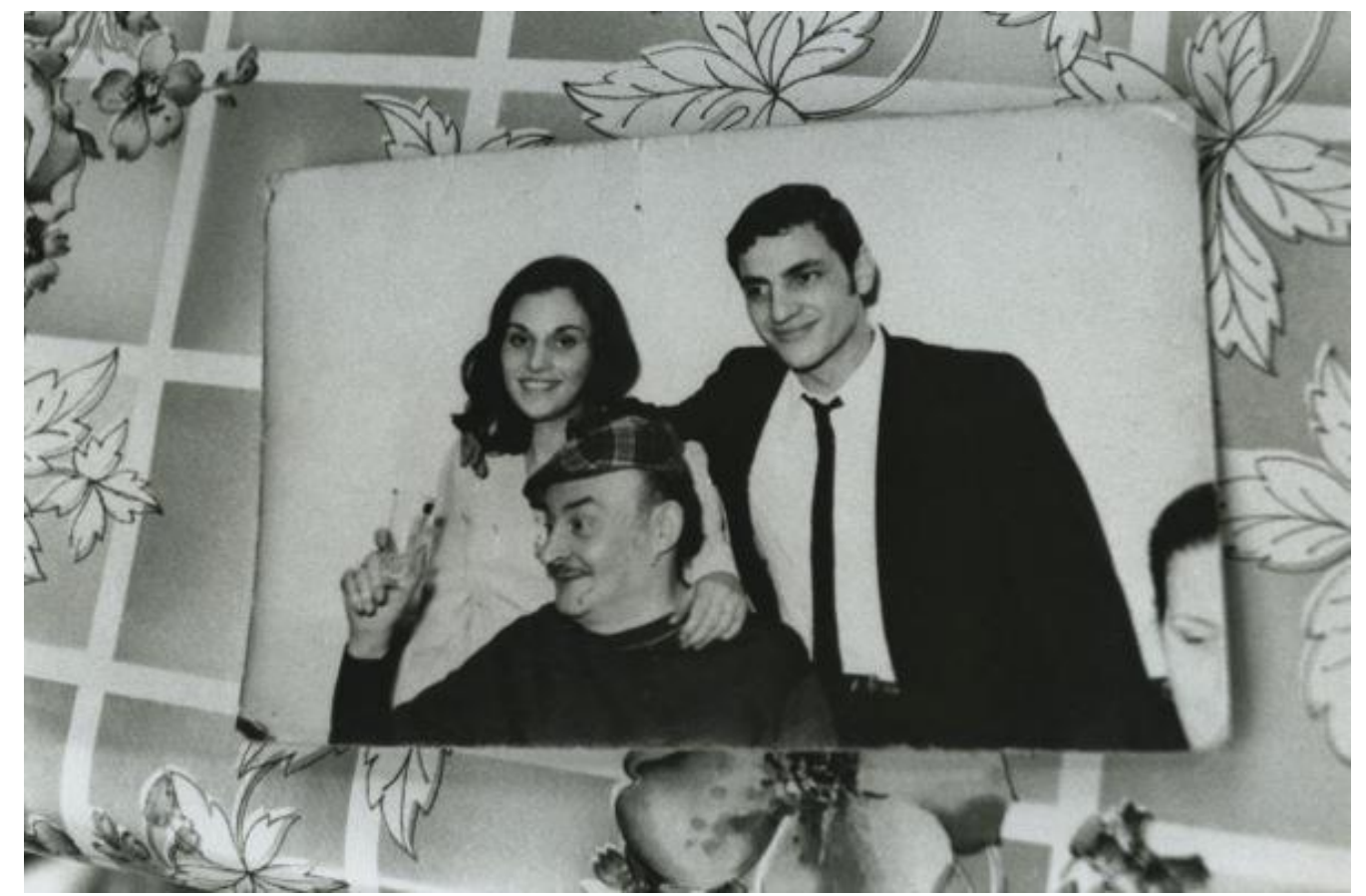

Foto 6 - Foto de família sobre uma mesa do café Chez Fabien et David, Belleville, Paris, Bairro $20^{\circ}$, (C) Sylvaine Conord. 
A foto 6 evidenciando uma outra situação ilustra bem essa ideia, dessa vez na França, em um café parisiense do bairro Belleville ${ }^{6}$ onde eu não tinha tido a autorização para tirar uma foto do rosto de meu interlocutor. Ele tinha me mostrado orgulhosamente uma foto de família que eu decidi fotografar depois de tê-la colocado sobre a mesa do café. Voltei mais tarde com a foto para lhe dar: ficou feliz de ter essa imagem aumentada e orgulhoso em mostrá-la a seus amigos. Como Christian Coiffier mostra bem no seu campo em Papuásia-Nova Guiné, se as fotografias não são apenas uma fonte de arquivos para os cientistas, elas são também uma fonte de lembranças para as populações locais. Voltar ao campo para dar as fotografias impressas em papel introduz um processo de interação particular dando início a uma relação de reciprocidade. Uma ligação de confiança se estabelece e a fotografia, simultaneamente dom de si e contradom do pesquisador, pode às vezes se transformar, através da intervenção ativa das pessoas fotografadas, em objeto de valorização e de pretexto para o negócio (Conord, 2000: 94). A tomada se dá muito pelas relações que se estabelece com as pessoas (Cartier-Bresson, op. cit.:10).

\footnotetext{
${ }^{6}$ Essa imagem faz parte de um corpus fotográfico constituído durante um trabalho de pesquisa sobre os modos de sociabilidade nos cafés de Belleville realizado em colaboração com Anne Steiner (socióloga, Universidade de Paris Oeste Nanterre La Défense).
} 


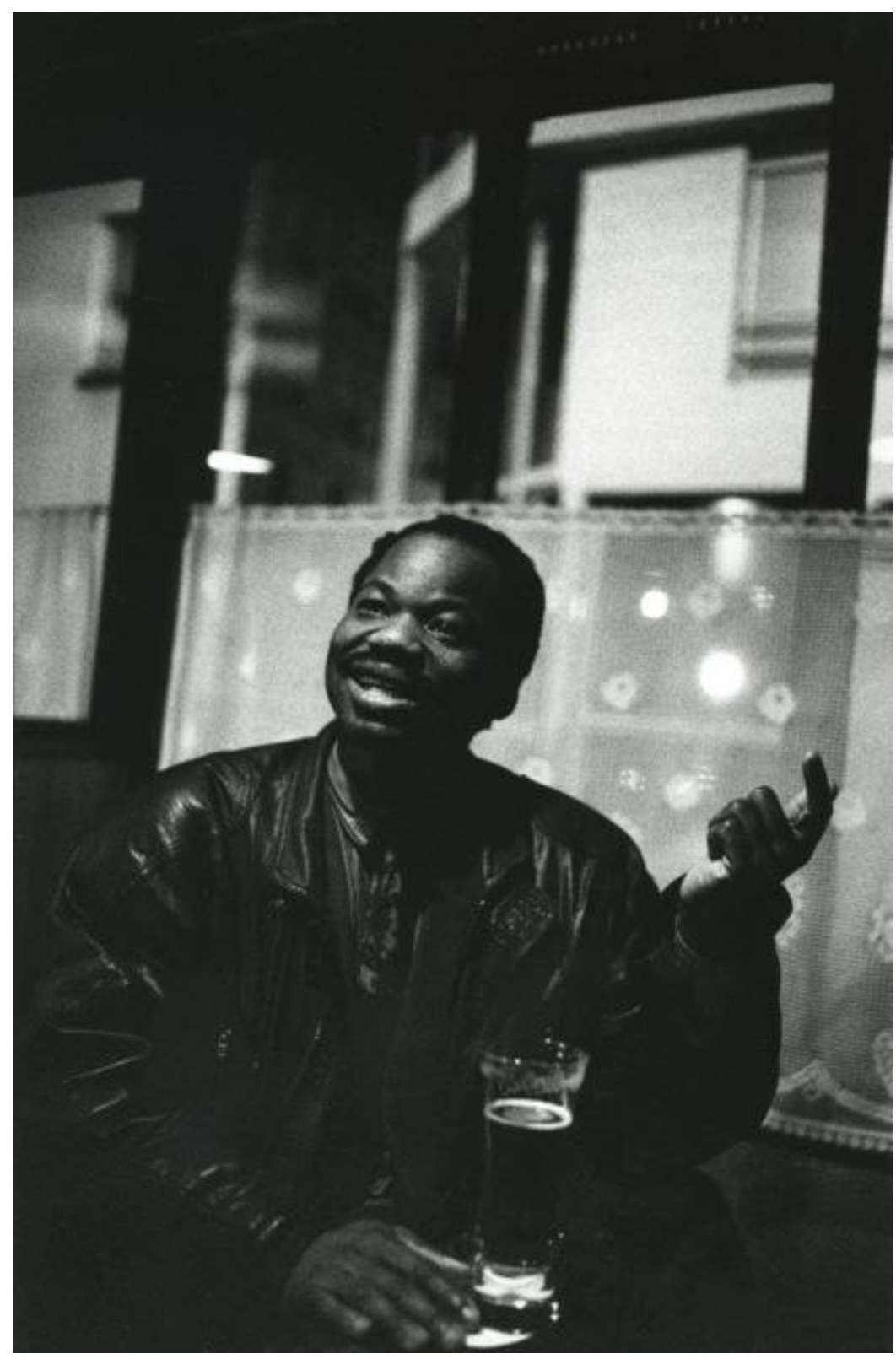

Foto 7 - Retrato no café Le bar des studios, Belleville, Paris, Bairro $20^{\circ}$, (C) Sylvaine Conord.

$* * *$

Por outro lado, mostrar as imagens sobre a tela da máquina fotográfica (no caso de uma tomada digital) permite compartilhar e orientar as escolhas de tomadas em função das observações dos atores. Isso encoraja esses últimos a participar das diferentes etapas de registro de imagens até a seleção que valorizará o melhor da auto mise en scène das pessoas fotografadas. Os indivíduos desejam se perpetuar em seus retratos e aspiram à posteridade. Através da imagem eles procuram a adulação, um certo 
reconhecimento de sua existência no instante preciso do clique fotográfico. Nos cafés de Belleville alguns gostariam de manifestar veemente sua presença, sua personalidade (foto 7). O café cria um contexto e um clima específicos favoráveis para uma mise en scène do cliente, seja ela direta ou pesquisada, individual ou coletiva (Conord, 1999). O olhar - tido sobre os outros ou sobre si - precede a comunicação verbal e ocupa um lugar central nos modos de sociabilidade. "Olhando aquele que olha (ou que fotografa), retificando sua postura, nos deixamos ser olhados como gostaríamos de ser olhado, damos a imagem de nós”, observa Pierre Bourdieu (Bourdieu, 1965: 120). O pesquisador se vê então atribuir o papel de retratista fotógrafo que deve cumprir precisamente com as demandas das pessoas. Essa situação encontrada com frequência em meus campos de pesquisa tinha como resultado, por vezes, novas funções que eu devia assumir: a fotógrafa de casamentos, de bar-mitsvah, de circuncisões ou de diferentes rituais que aconteciam durante as peregrinações (Conord, op. cit.: 104). Esse tipo de situação oferece a possibilidade de ter acesso a lugares inexplorados do campo e favorece as trocas que se tornam cada vez mais intensas conforme o andamento da pesquisa.

\section{Cruzamento de olhares}

O pesquisador não pode se contentar com essas imagens mostrando auto mises en scènes das pessoas fotografadas. Ele deve produzir igualmente seu próprio corpus a partir de suas observações fazendo fotos não posadas, imagens que mostram o contexto da tomada (cenário, ambiente, enquadramentos decentralizados, paisagens urbanas, vistas de conjunto, fluidos para expressar o movimento, etc., foto 10). Disso resulta a realização de um grande número de fotografias favorecidas e facilitadas pelas novas técnicas de tomadas digitais. Com efeito, o desenvolvimento da utilização de novos materiais audiovisuais cria formas de escrita inovadoras (Chevalier, Mayor, Schoeni, 2008). A diversidade dos eventos observados, por exemplo, os constrangimentos temporais e materiais (no caso de um campo afastado como uma peregrinação na Tunísia) incitam a registrar diversos documentos em série, memorizando assim os traços de um desfilamento rápido de gestos e de movimentos que o olho apenas não conseguiria distinguir (Arrêt sur images, 2007). Marcel Mauss indicava em seu curso de etnografia: "Nunca se fará fotos demais, desde que elas sejam comentadas e muito bem situadas: hora, lugar, distância. Essas indicações serão indicadas ao mesmo tempo no 
filme e no diário de campo" (Mauss, 1967: 16-22). A tomada sistemática em cada etapa da pesquisa constitui o que chamo de diário de campo visual (Conord, 2006) que vai dar sequência ao bloco de notas. A re-observação das imagens gravadas permite em seguida um distanciamento em relação ao campo. Albert Piette evoca sobre esse assunto o princípio de isomorfismo que implica a presença na imagem de todos os traços que receberam a impressão luminosa sejam eles intencionais ou não (Piette, op. cit.). $\mathrm{O}$ procedimento de registro fotográfico é de fato considerado por muitos pesquisadores como uma maneira de alargar nosso ângulo de visão e nossa capacidade de memorização visual.

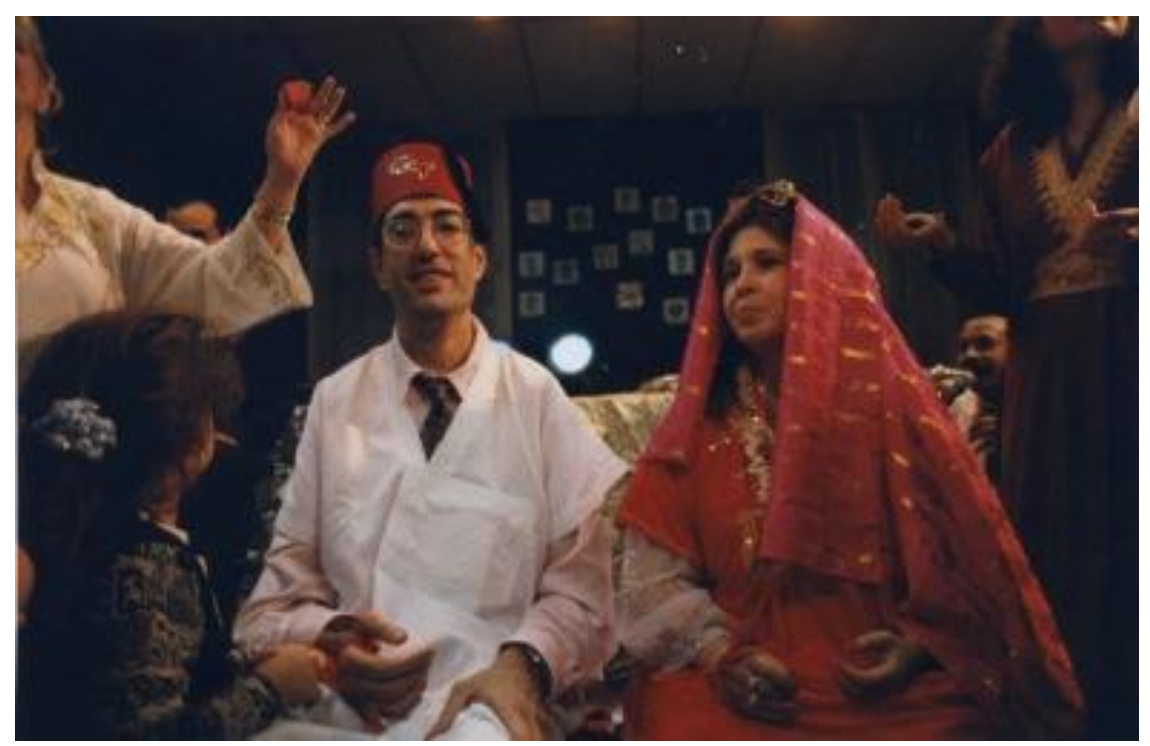

Foto 8 - Encontro chamado hena que precede um casamento judeu tunisiano, Paris, Bairro $19^{\circ}$, (C) Sylvaine Conord.

No âmbito de trabalhos sobre os aportes da fotografia a partir de uma pesquisa sobre tunisianas que frequentavam o bairro Belleville (Conord, 2000, 2002), fui levada a fazer imagens que dizem respeito a certos costumes e ritos judeus tunisianos. Os encontros essencialmente familiares que precediam o casamento dentre eles o "hena" (durante o qual hena é colocada no centro da palma da mão para dar sorte aos futuros marido e mulher) representaram uma ocasião de memorizar através da imagem fixa uma multitude de detalhes graças a mudanças de foco da grande-angular (foto 8) para um 
enquadramento aproximado (foto 9). Os costumes e suas cores, o ruban vermelho amarrado na mão para dar sorte, tipos de jóias oferecidas, expressões do rosto e do corpo, tantos elementos que interessam o etnólogo em sua investigação. A ausência de auto mise en scène significa o esquecimento da presença da fotógrafa que participa das ações e se funde assim no cenário. Por consequência, esta obtém poses mais naturais e tem toda a tranquilidade para fazer imagens em série a fim de reconstituir os movimentos e o ambiente. Podemos fazer um parêntese aqui, sobre o interesse em utilizar às vezes a gravação de imagens animadas que teriam como função completar o corpus de imagens fotográficas em algumas circunstâncias. A fotografia é fixa e muda. Os encontros de judias tunisianas que dançam são sonoros e movimentados, a câmera parece então um bom instrumento para captar esse ambiente e prolongar o método de variação dos ângulos de vistas. ${ }^{7}$

\footnotetext{
${ }^{7}$ Um colóquio sobre o tema "Arrêt sur images. Pour une combinaison de la photographie et du film" ocorreu no Museu do Quai Branly em Paris, nos dias 09 e 10 de abril de 2012. Os Anais do Colóquio se encontram publicados na internet.
} 


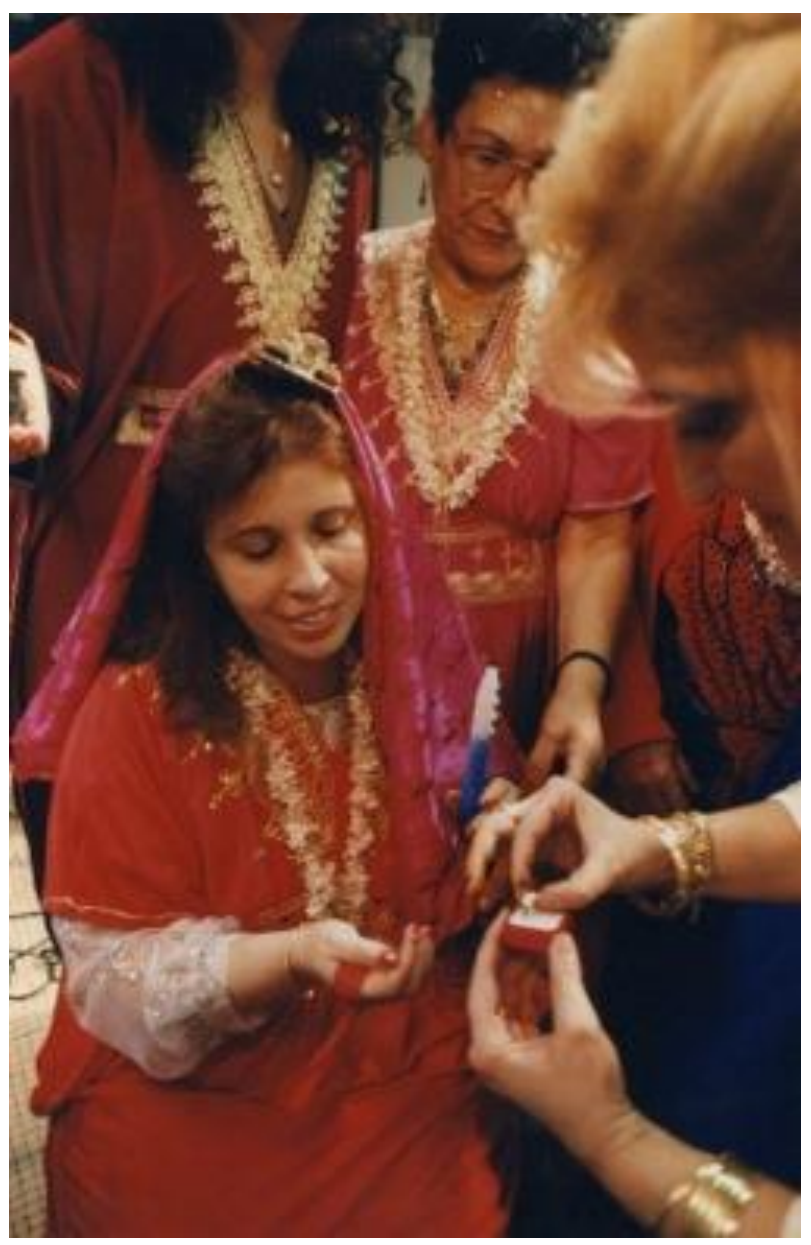

Foto 9 - Hena, detalhes da cena. Colocação das jóias de ouro na noiva, @ Sylvaine Conord.

No entanto esse método tem limites. Não se trata também de fotografar por todos os lados e sem parar. O pesquisador fotógrafo vai escolher dirigir seu olhar sobre uma vista de conjunto ou ao contrário sobre um detalhe (foto 9). O zoom permite esse exercício graças a suas focais variáveis. Seja com ou sem máquina fotográfica, há desde o início um trabalho de seleção, de organização, de interpretação e de orientação da atividade perceptiva. É então importante cruzar os diferentes dados oriundos das diferentes tomadas, da realização de entrevistas e de um bloco de notas. Essas imagens produzidas de acordo com os critérios do pesquisador (que podem ser de ordem social, cultural ou estética) podem provocar uma reação nas pessoas fotografadas. Clientes do café de Belleville La Vielleuse rejeitaram completamente minhas fotografias feitas em preto e branco: elas associavam o preto e os contrastes com a morte, e como usavam roupas com cores brilhantes, eles preferiram que se valorizassem estas (Conord, 2000, 
op.cit.). A leitura da imagem não é nem universal nem natural: ela é antes de tudo cultural. O olhar sobre uma imagem (ela mesma fruto de um olhar), não pode mais ser compreendido como um "registro passivo" de acordo com os termos de Jean-Pierre Terrenoire (Terrenoire, 1985: 513): ele é obrigatoriamente interpretativo.

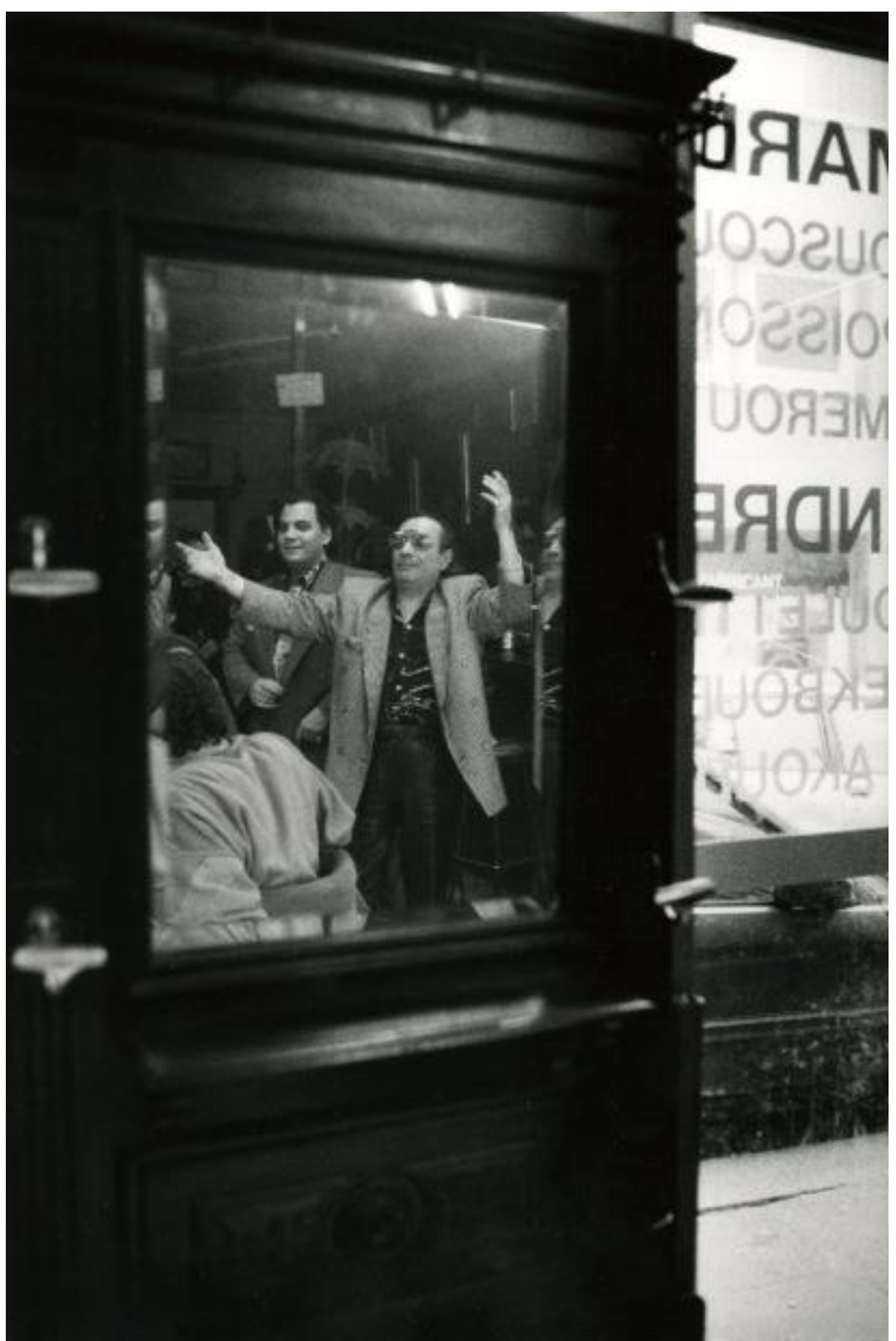

Foto 10 - Café Miroir, @ Sylvaine Conord. 
Assim, da tomada à leitura da imagem feita em papel, a fotografia, de sua concepção a sua percepção, encontra-se no centro de um sistema complexo de realidades individuais e sociais. Mas, segundo minha hipótese, essa dimensão da imagem fotográfica, longe de constituir um obstáculo metodológico, representa um trunfo para o pesquisador. Pois, como observa Jean-Paul Terrenoire, "na imagem, como no discurso, remetente, mensagem, destinatário estão co-presentes. A imagem se dá, portanto como matriz de uma relação social e, de fato, cai por inteiro no campo das ciências sociais" (ibidem: 514). No entanto, a fotografia foi criticada por muito tempo e rejeitada do campo da pesquisa científica devido a seu caráter subjetivo ou estetizante. Mas, o lugar que ela ocupou na história de nossa sociedade, a função que ela tem na transmissão da memória coletiva e individual, as diversas funções que ela preenche enquanto modo de representação de si bastam para considerá-la como um suporte de pesquisa pertinente nas ciências sociais.

\section{Conclusão}

A fotografia, disposta no centro do processo de investigação de um campo facilita e enriquece as relações que existem entre o pesquisador e o meio estudado. Ela levanta muitas questões sobre a maneira que a pessoa fotografada se representa, e sobre as escolhas do antropólogo em representar "o outro". Efetivamente, a imagem fotográfica não é um espelho do real, ela é o resultado das escolhas subjetivas da pessoa que fotografa e das escolhas de mise en scène das pessoas fotografadas. As diferentes experiências de fotografias na periferia de Paris, no Marrocos e nos cafés de Belleville mostram que o suporte visual compreendido como meio de trocas e de memorização nos esclarece sobre as situações observadas, mas igualmente sobre a pessoa fotografada que às vezes negocia sua imagem. Da fase do reconhecimento do lugar a da representação de si ao "outro", as escolhas de tomadas refletem igualmente o tipo de relação que tem o pesquisador com seu campo. Assim, saberemos que a imagem não tem apenas como função ilustrar resultados de pesquisa. O cientista pode utilizá-la como um verdadeiro instrumento de pesquisa com múltiplas funções. 


\section{Referências}

AUMONT, Jacques. L'image. Paris: Nathan, 1990.

BECKER, Howard S. "Photography" ("Photography and sociology", "Do photographs tell the truth?", "Aesthetics and truth"). In: Doing things together: selected papers. Evanston Illinois: Northwestern University Press, 1986. p.221-317.

BOURDIEU, Pierre. Un art moyen. Paris: Ed. de Minuit, 1965.

BROMBERGER, Christian (org.). Passions ordinaires. Du match de football au concours de dictée. Paris: Bayard, 1998.

CARTIER-BRESSON, Henri. "L'instant décisif". In: Les cahiers de la photographie, $n^{\circ}$ especial Henri Cartier-Bresson. Villeurbanne: Centre National Des Lettres,1985. p. 9-20.

CHEVALIER, Sophie; MAYOR, Grégoire e SCHOENI, Dominique (Org.). "La narration dans tous ses états : nouvelles technologies, nouvelles questions?". In:

ethnographiques.org, n.16 - [on line]. Besançon: Université de Franche-Comté; Neuchâtel: Université de Neuchâtel, 2008. Disponível em: http://www.ethnographiques.org/2008/Chevalier,et-al.html.

COIFFIER, Christian. "Safari photo et chasse aux têtes en Nouvelle Guinée". In:

Journal des anthropologues, Questions d'optique, Aperçus sur les relations entre la

photographie et les sciences sociales. Paris: AFA-MSH, 2000. p. 259-281.

COLLIER, Jr. John ; COLLIER, Malcolm. Visual anthropology: Photography as a research method. Albuquerque: The University of New Mexico Press, 1986.

CONORD, Sylvaine. "Anthropologie visuelle des mal-logés de la place de la

Réunion”. In: Image et société. LA ROCCA, Fabio (Org.). Revista $m @ g m @$ (on line), v.6. Catania: Observatoire Processus Communications/ Association Culturelle Scientifique, 2008.2 Disponível em: http://www.analisiqualitativa.com/magma/0602/article_02.htm .

CONORD, Sylvaine. "La photographie à usage scientifique: le journal de terrain visuel". In: TAMAROZZI, Federica; PORPORATO, David (Org.). Ogetti immagini, Espereienze di ricerca ethnoanthropologica. Torino: Omega Edizioni, 2006. p. 177196.

CONORD, Sylvaine. "La photographie comme méthode appliquée à l'étude des

bars". In: DESJEUX, Dominique; JARVIN, Magdalena et TAPONIER, Sophie (Org.). Regards anthropologiques sur les bars de nuit. Espaces et sociabilités. Col. Dossiers

Sciences Humaines et Sociales, Cap. III. Paris: L'Harmattan, 1999. p. 83-112.

CONORD, Sylvaine. "Le choix de l'image en anthropologie: qu'est-ce qu'une 'bonne' photographie? ". In: Ethnographiques.org, 2, [on line]. Besançon: MSHE Claude Nicolas Ledoux/ Université de Franche-Comté; Neuchâtel: Institut d'ethnologie/ Université de Neuchâtel, 2002. Disponível em:

http://www.ethnographiques.org/2002/Conord.html .

CONORD, Sylvaine. " 'On va t'apprendre à faire des affaires...' Echanges et

négoces entre une anthropologue-photographe et des Juives tunisiennes de

Belleville". In: JEHEL, P-J ; MARESCA, S. ; MARZOUK, Y. (Org.). Questions d'optiques. Aperçus sur les relations entre la photographie et les sciences sociales. Journal des anthropologue, n.80-81. Paris: Association Française des Anthropologues Maison des Sciences del'Homme, 2000. p.91-116.

DE FRANCE, Claudine. Cinéma et anthropologie. Paris: MSH, 1982.

DUBOIS, Philippe. L'acte photographique. Paris: Nathan, 1990.

MAUSS, Marcel. Manuel d'ethnographie. Paris: Payot, 1967.

PIERCE, Charles Sanders. Ecrits sur le signe. Paris: Le Seuil, 1978. 
PIETTE, Albert. "Fondements épistémologiques de la photographie". In: CONORD, Sylvaine (org.). Arrêt sur images, Photographie et anthropologie. Ethnologie française, v.37, 2007/1. Nanterre: PUF, 2007. p. 23-28.

TERRENOIRE, Jean-Paul. "Images et sciences sociales: l'objet et l'outil". In:

Revue française de sociologie, XXVI-3. Paris: CNRS/ Presses de Sciences Po, 1985. p. 509-527.

Recebido em: 20/04/2012

Aprovado em: 17/09/2012 